Tatsache, daß so viele Faktoren bei der Nutzung internationaler Wasserläufe von Bedeutung sind, ist eine umfassende Feststellung der völkerrechtlichen Regeln für diese Nutzung von erheblicher Bedeutung. Das Internationale Wasserrecht, so weist Ule nach, könnte ein wesentliches Hilfsmittel zur Lösung internationaler Wasserkonflikte werden. Angesichts der zunehmenden Politisierung dieses Themas hat der Autor es vermocht, einen wissenschaftlichen und konstruktiven Beitrag zur Lösung internationaler Wasserkonflikte zu leisten. Es bleibt zu hoffen, daß das Buch demnächst in die englische Sprache übersetzt wird, damit es auch Lesern anderer Länder zur Verfügung steht.

Annette van Edig

\title{
Matthias Pape
}

\section{Humanitäre Intervention}

Zur Bedeutung der Menschenrechte in den Vereinten Nationen

Nomos-Verlag, Baden-Baden, 1997, 350 S., DM 56,--

Die politikwissenschaftliche Arbeit Papes, 1996 in Freiburg an der Philosophischen Fakultät als Dissertation angenommen, entstand zwischen 1993 und 1996. Sie geht der Frage nach, "welche Rolle die Menschenrechte in den Vereinten Nationen spielen und welche Schwierigkeiten der Durchsetzung der Menschenrechte im Wege der humanitären Intervention (i.S.v. militärischem Eingreifen) und der humanitären Hilfe entgegenstehen" (S. 11). Gleichzeitig will das Buch einen Beitrag zur Diskussion über die universale Begründung und Verwirklichung der Menschenrechte sowie einer Reform der UNO leisten, indem es "Zielkonflikten, Schwierigkeiten und Hemmnissen (...) nachspürt" (S. 302); es bietet jedoch trotz seines vielversprechenden Untertitels eine eher lückenhafte Auseinandersetzung mit dem Thema.

Nach einer generellen Einleitung ist das Buch in fünf Hauptabschnitte eingeteilt. Erstes Thema ist 'Der universale Menschenrechtsstandard als Schutzgut der humanitären Intervention', eingeschränkt auf die Fundamentalnormen Recht auf Leben, Verbot von Folter, Sklaverei und Diskriminierung.

Im zweiten Bereich 'Klassische humanitäre Intervention und humanitäre Hilfe' bestätigt Pape das Ergebnis anderer Autoren, "daß die humanitäre Intervention dann nicht gegen das Interventionsverbot verstößt, wenn sie die (...) Menschenrechte betrifft" (S. 90).

Im äußerst knapp gehaltenen dritten Teil 'UNO-Intervention: rechtliche Grundlagen' analysiert er Art. 39 und 41 UN-Charta und stellt klar, daß es sich bei Maßnahmen, die vom Sicherheitsrat ergriffen werden, aus rechtlichen Gründen nicht um 'humanitäre Intervention' handeln kann. Obwohl er den Unterschied zu militärischer Gewalt erläutert, findet der Verfasser keinen neuen Begriff, sondern behält 'humanitäre Intervention' inkonsequenterweise bei. 
Im vierten Kapitel 'UNO-Intervention: Einzelne Interventionen' stellt Pape einzelne Fälle von Interventionen ausführlich dar, hauptsächlich Irak, Somalia, ehemaliges Jugoslawien Abschnitte, die Kennern dieser Themenbereiche keine neuen Einsichten bieten, aber durchaus gut erarbeitet sind.

'Humanitäre Intervention: Zur Bedeutung der Menschenrechte in den Vereinten Nationen' ist das abschließende Kapitel. Auch hier vermischt Pape politik- und rechtswissenschaftliche Aspekte. Dem Völkerrechtler nicht 'juristisch' genug, dem Politologen nicht 'politikwissenschaftlich' genug (so der Verfasser selbst) - käme die Arbeit zu tragfähigen neuen Erkenntnissen, könnte sie den interdisziplinären Ansatz als Stärke verbuchen. Dieser Versuch Papes erscheint nicht ganz gelungen, da lediglich in groben Ansätzen herausgearbeitet wird, unter welchen Voraussetzungen die Menschenrechtssituation verbessert werden könnte.

Die Dissertation kann man als eine Art fundierten Zwischenbericht ansehen. Wirklich neue Wege weist sie nicht auf.

Dagmar Reimmann

\section{Eberhard Stabreit}

Der völkerrechtliche Status der Transkei, Ciskei, Bophuthatswanas und Vendas während der Zeit ihrer formellen Unabhängigkeit von der Republik Südaf rika Peter Lang Verlag, Frankfurt am Main, 1997, 199 S., DM 79,--

Zwischen 1976 und 1981 wurden die homelands Transkei, Ciskei, Bophuthatswana und Venda - auch independent states oder nach ihren Anfangsbuchstaben TBVC-Staaten genannt - von der Republik Südafrika in die formelle Unabhängigkeit entlassen. Hauptzweck war die Ausbürgerung großer Teile der schwarzen Mehrheitsbevölkerung zur Sicherung der weißen Vorherrschaft in Südafrika. Die Staatengemeinschaft hat diesen Staaten stets die Anerkennung verweigert. Die völkerrechtliche Rechtfertigung dieser Politik ist jedoch bis heute umstritten. Auch wenn der status quo ante durch Reintegration der Staaten in das Hoheitsgebiet Südafrikas im Zuge der Abkehr von der Apartheidspolitik 1994 wieder hergestellt wurde, bleibt das Problem, inwieweit effektive Territorialgewalten, deren Entstehung oder Existenz mit gravierenden Verstößen gegen völkerrechtliche Normen belastet ist, die aus dem Völkerrecht entspringenden Rechte eines Staates gegenüber der Staatengemeinschaft in Anspruch nehmen können, weiterhin aktuell. Dies gilt insbesondere im Hinblick auf die unter Anwendung physischer Gewalt entstandenen lokalen Territorialgewalten auf dem Balkan oder dem Gebiet der ehemaligen Sowjetunion.

Den Ausgangspunkt bei der Bewertung der Völkerrechtssubjektivität der TBVC-Staaten bilden die herkömmlichen Merkmale der Staatlichkeit, die zugleich Kern der Untersuchung sind. Vorangestellt wird eine ausführliche historische Betrachtung, in der die Besonderhei- 